\title{
A FINGERPRINT MATCHING ALGORITHM
}

\author{
H.I. Wahhab ${ }^{1,2}$, haider.wahhab@uokerbala.edu.iq, \\ A.N. Alanssari, ${ }^{1,3}$, alaan.azeez@uokufa.edu.iq, \\ D.S. Rozhina1, asp17rds604@susu.ru, \\ A.V. Agafonov', asp17aav494@susu.ru \\ ${ }^{1}$ South Ural State University, Chelyabinsk, Russian Federation, \\ ${ }^{2}$ University of Karbala, Karbala, Republic of Iraq, \\ ${ }^{3}$ University of Kufa, Najaf, Republic of Iraq
}

\begin{abstract}
Fingerprint pattern knowledge is largely applied in many fields such as access control and identity administration. This is however associated with some problem of automatic fingerprint recognition and therefore this has rendered to the use of the most known method that is biometric identification. Every finger of the hand shows a different pattern of ridges and depression different from the other finger and this pattern remains sole and constant thus helping in identity since fingerprint pattern from one person is different to that of another person. This pattern may alter whenever there are cuts and bruises in the outer part of the finger. Fingerprint pattern recognition method includes the following steps: firstly, matching of the fingerprint which includes the pattern based method and the minutiae method. Secondly, the used algorithm in the recognition and comparing of the fingerprint images. Thirdly, the image enhancement process that helps to improve the quality of the fingerprint pattern and forth the reduction of the size of the image which includes identification of the region of small minutiae and actual minutiae. The objective of this research is recognition of the fingerprint pattern.
\end{abstract}

Keywords: fingerprint matching, image enhancement, segmentation, Gabor filter.

\section{Introduction}

In modern days the improvement of technology, identification of people using fingerprints has been made easy by use of biometric gadgets which identifies a person using different patterns of their finger though this is enshrined by some challenges of the existence of automatic fingerprint structure thus making the work of identification specifically amusing as well as trying [1]. Through technology, features of people are recognized through studying their fingerprint pattern [2]. The use of biometric technology will continue being applied in many years to come. A person's fingerprint is identified based on ridges and bifurcation. This has enabled the government to be able to identify criminals and their day to day operations. This research is structured as follows. First section literature review which involves comparison characteristic isolation as well as segmentation. Second section. fingerprint matching by looking on bifurcation and the ridges by use of the matching method. Third section existence of algorithm which depends on the pattern approach of the whole fingerprint. Fourth section segmentation and binarization where a grey image is converted to a binary image and in conclusion the algorithm show the improvement of the whole process.

\section{Literature review}

There are numerous methods used in the area of identification and comparison of the images of the fingerprints. The correspondence of a given method involves several stages, for example, the improvement segmentation removal of the comparison characteristics isolation among others. The description of the proposed method is given below.

The explanation of the method based on less as far as the recognition and identification of fingerprint images were made by Asif Iqbal Khan with the help of others. Authentic minutiae, as well as division points, are removed by use of the cross-numbering technique. The technique, in this case, made use of the 4 by 4 window as opposed to the 3 by 3 window so as to banish the similar points. Prior to making an improvement on the image of the removal process, the binarization thinning and thoroughness marking is performed. Duplicate division point of the 3 by 3 window is detected and eliminated using the false detail elimination method. Following the application of the suggested solution, the number of authentic division points rose by roughly $55 \%$ and all the former lost division points included [3]. 
A new method that effectively uses Euclidean distance in the recognition of fingerprints is introduced by Ala Baltiet. The Euclidean distance formulates the gap between the center areas relative to the division minutiae of the closest neighbor. This technique is very effective in that it minimizes the number of features vectors while at the same time avoiding the issue of rotation as well as geometric alteration during the accession stage of the fingerprint image. The new method initially establishes and improves the center point. Following the removal of the characteristics the Euclidean distance is established. A normalization process is then conducted following the abbreviation of the Euclidean distance [4].

PCA (Analysis of the main components) used to obtain the analytical features of the ROI so as to come up with a vector of characteristics. The principal component analysis converts an MXN resemblance into vector modules in rows and columns. The principal component analysis has normalized feature vectors by choosing vectors which exhibits unusual characteristics. Here the PCA runs only in the ROI as opposed to the whole image of the fingerprint. The Euclidean distance between two vectors of the features obtained from ROI is calculated following the application of the principal component analysis. This technique relies on the central point of the fingerprints resemblance since the poor quality images contribute to the failure to sense the central position [5].

\section{Fingerprint matching}

The application of the law has successfully used the comparison of fingerprints for over a hundred years. Nowadays this knowledge is widely used in many fields such as character administration as well as regulation of admittance. An automatic structure of fingerprint Recognition and identity are the foremost [6]. Challenges and prospects for exploration in the field.

The most common and widely used method for fingerprint recognition is the biometric identification. There are three main patterns of fingerprints:

- Arches ( $5 \%$ of the population);

- Loops (70\% of the population);

- Whorls (25\% of the population).

Fingerprints remain constant until the whole life of the person. Minutiae extensively used for recognition of fingerprints and classified as bifurcation and ridge ending. The minutiae matching is used for comparing the template data with the fingerprint. For the effective matching process, the mined data is kept in the matrix arrangement [7].

There are three components that can be derived from a fingerprint portrait:

- Fingerprint arrangement is enormous and detailed like the crest and the configuration type;

- Small details that mark in which Bifurcated folds or at the end;

- Openings shape of the edge incipient crest crack folds as well as other lasting details.

Federal Bureau of investigations in the United States automated fingerprint system which is the world's largest fingerprint recognition system. Since 199960 million people's fingerprints are contained in IAFIS country with relevant demographic information and give the dormant printed investigation for criminal inquiry and documentation of ten copies for the identification of suspects and confirmation from the general population [8].

During 2008 Federal Bureau of investigation begun upgrading Integrated Automated Fingerprint Identification to the next level documentation structure that will provide a further biometric structure which includes palm aqueous as well as facial printing [9].

The skin of our palms and sole shows a pattern similar to the flow of folds and depressions. These papillose edges found on fingers referred to as the friction folds benefit the palm grip item using cumulative abrasion as well as enlightening the physical detection based on the superficial structure. This sidebar abrasion fold pattern explains the course and essence of the above-mentioned features [10].

Additional significant in the help of the crest of abrasion is identifying people. The arrangement based on the resistance of folds of every finger remains exclusive as well as constant allowing it in helping a sign of recognition. By use of a fingerprint, it is possible to differentiate identical twins based on their fingerprint pattern. The evident lesions which include bruises and cuts on the outer part of a finger temporarily alter a model in the part that is damaged: sudden folds systems are seen thereon healing of the injury [11].

Henry Faults, Edward Henry and Francis Galton amongst many came up with scientific platforms for the application of fingerprints in the identification of people at the conclusion of the 19th century. 


\section{Информатика и вычислительная техника}

The governments through the relevance agencies mandated with maintaining order have been using fingerprints to identify culprits in crimes as well as for routine identification purposes. Around the world, the use of fingerprints have been a very vital procedure for two principal reasons [9]:

- Revealing or exposing the culprits in a given crime;

- The identification of serial offenders in various criminal activities

\subsection{Methods of Fingerprint Matching}

Many methods have been applied in the process of recognizing fingerprints. The basic correspondence between the models of the fingerprints to identify as well as the many models already known would not attend well owing to its high compassion for errors. This article seeks to analyse two critical methods for fingerprints:

The pattern-based method;

The minutiae-based method.

The minutiae-based methods are usually based on establishing matches between the minutia points in the first and the first copy fingerprint images [12]. The systems usually work effectively with highquality fingerprint images and an adequate fingerprint area. This implication is more pronounced in fingers which are of poor intrinsic quality in which only a subset of the minutiae can be mined and used with a satisfactory reliability [13].

The outdated version algorithm used for levelling fingerprints positioning places was established on a low pass filter. To further develop this algorithm we suggest a shifting window adaptive flattening algorithm as a basis for fingerprint inclination fields dependent on the reliability of the fingerprint inclination. Further methods to attenuate the fingerprints is the median filter [14].

A fingerprint assessment form calculates a matching score between two different fingerprints which are usually high for the fingerprints within the same finger as well as low for the fingerprints of differing fingers. The contrast of fingerprints is a great problem of recognition of the motif as a result of the high differences in intraclass (differences in the appearance of the fingerprints of the same finger) and a tremendous resemblance between the appearances of the fingerprints of different fingers. The main reasons for the variations witnessed can be attributed to the positioning of the fingers with reverence to the sensitive parts as well as the state of the fingers in terms of dryness or cuts of the skin. There are three types of fingerprint templates.

The contrast of fingerprints has been in use effectively for a very period of time. In the current modern world, it's possible to find various applications, for instance, the access control as well as

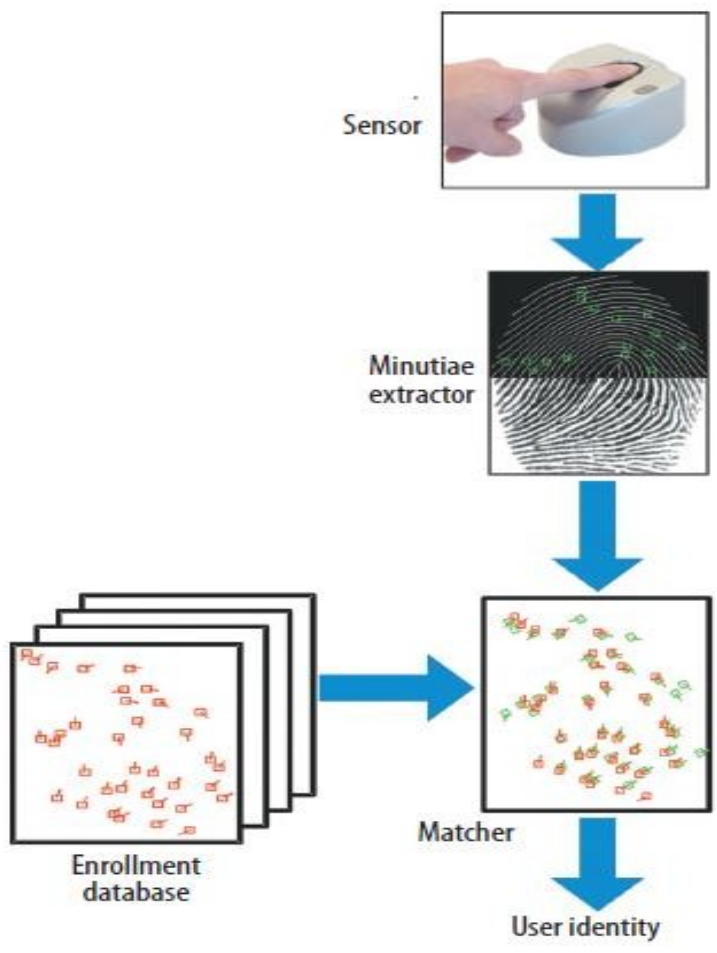

Fig. 1. Fingerprint identification system identity management systems. The main test for field research, as explained by authors' remains in the description of the automatic system used in sensing and identifying the fingerprints as shown in Fig. 1.

In the initial phase of documentation, a person touches a sensor which produces a query impression in form of a duplicate to the original fingerprints. The query impression helps in giving minutiae points so that a comparison can be established between the queries raised with the templates already located within the database used for registration purposes so as to come up with the exact number of minutiae points. Since there are many differences that occur as a result of compression as well as fingerprint placement, the minute points obtained from the model as well as the fingerprints should be recorded prior to the to the correspondence. After the fingerprints are brought in line, the meter establishes the actual number of the related minutiae group of two which have the same position and trajectory. The critical function of the system is to govern the user's identity by connecting the score of the game with a given limit fixed by the administrator [9]. 


\subsection{Comparing pattern based and minutiae method}

The most effective and accurate technique of biometric data is through the comparison of fingerprints. A person's identity is easily established since the fingerprints aids in the recognition process [15]. As far as the minutiae method algorithm is concerned, it's only the local features that are removed from the image of the fingerprint. On the other hand, the method of comparing pattern usually makes use of the whole area covered by the image from the fingerprint. It effectively makes use of the local as well as the global characteristics associated with a given fingerprint image. The new algorithm technique is classified into three stages. The first stage involves the improvement of the image in terms of quality with the limit values set as well as the reduction of the proportional space of the fingerprint image by making a relevant analysis of the main parameters or components. The analysis of the main component contains the main components in the space less dimensionality with respect to the high value's data.

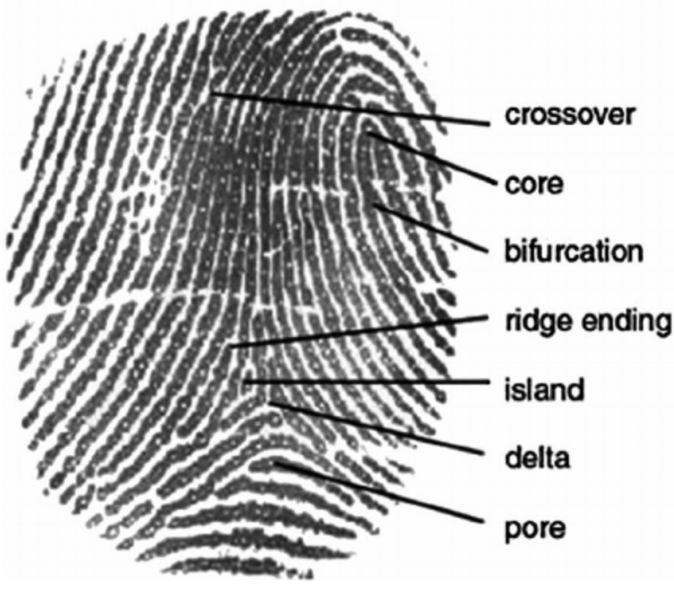

Fig. 2. Formation of fingerprint In the second stage of the pattern based technique, the feature vectors are removed from the image of the fingerprint as well as form the feature map by making use of the Gabor filter. The third stage of the technique basically deals with the calculation of the Euclidean distance between two points in the maps to establish whether there is any similarity between the images or not [6].

The image of a fingerprint is conventionally made up of minute points, valleys, ridges as well as local and global properties. The small lines in the fingerprint image represent the tiniest point. The highest extreme in the image is represented by the central part which is located in the inner area. The valleys in the image are represented by the white lines while the edges are the black section of the image as shown in Fig. 2 [16].

The background space is made up of noise while the foreground comprises the largest part of the information. The global functionality contains the complete formation of the image of the fingerprint while the local characteristics are basically the individual areas of the image as shown in Fig. 3 b.

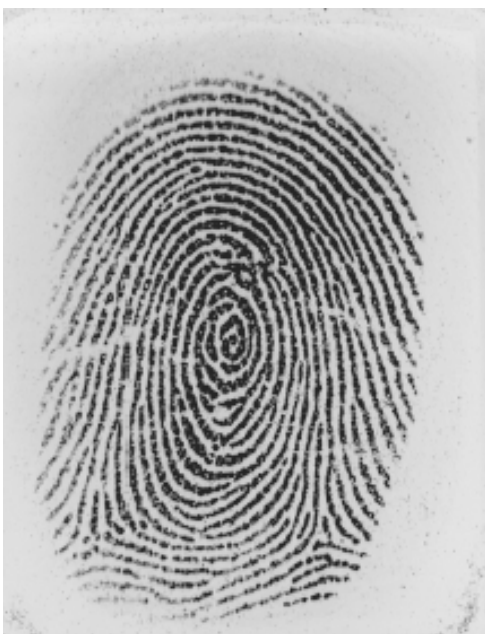

a)

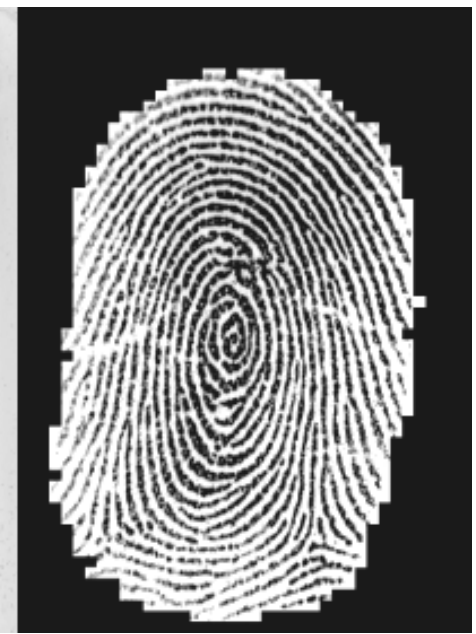

b)

Fig. 3. Fingerprint Segmentation: a - Input Image; b - Output Image

\section{Existing algorithm}

The current algorithm hinges on the point of view of the trifles and made use of local characteristics of the image that led to inaccurate findings since it includes some image parts of the fingerprint and omitted some specific points which are vital for matching the images of the fingerprints. The suggested algorithm depends on the pattern approach that comprises the whole formation of the fingerprint image. This algorithm makes use of both local and globally conventional fingerprint image [17]. Application of 


\section{Информатика и вычислительная техника}

dust and oil contributes to noise on the image of the fingerprints when detecting the fingerprints using the sensors. The use of sensors with low quality leads to distortion in the image of the fingerprints. The use of image enhancement ensures that all types of noise and negative effect are effectively erased.

The gaps and breaks in the image of the fingerprints constitute the spurious minutiae. These gaps occur during the thinning and binarization in many cases. They can be removed through the application of artificial minutia removal techniques.

The search for minute correlation points creates problems and makes the algorithm more expensive. Match minutiae are not concerned if two fingerprints which are intertwined together are combined. However, they must find minutia related to the same address [18].

\section{Proposed work}

In our algorithm we dealing with four steps of preprocessing and post processing as the following.

\subsection{Image Enhancement}

Before extracting the minutiae it is necessary to improve the image in some images of the lowquality fingerprints. The image improvement is obtained by the intensity regulation technique based on the limit. This technique is vital in changing the strength levels of the image of the fingerprint. The strength magnitude changes from (0.255) levels. After choosing a given area, it creates the strength level of that given area and comes up with the limit values of the strength levels [19]. The limit value dictates how much strength or intensity needs to be altered or not. The MATLAB corollary which is used represents an incorrect setting for this technique.

\subsection{Segmentation and Binarization}

The process of binarization involves converting a gray image into a binary image so as to make improvements in the contrast between the valleys as well as ridges within the image of the fingerprints which leads to minutiae extraction. The process of binarization determines the value of all the pixels within the enhanced image of the fingerprint and if the figure is large that the global limit, the value of the pixel is set to zero or to a binary value [20].

The critical role played by the process of segmentation is the definition of the various parts in which the image of the fingerprint belongs to. This involves the determination of the places which contains noise and distortions. The grooves are contained in the background which represents the irrelevant parts of the image while the crests are contained in the foreground as well as the relevant parts. Layout filters are used in the segmentation of the plot [21], as shown in Fig. 3b.

\subsection{Principal component analysis}

The major role played by the principal component analysis is the reduction in the size of the image of the fingerprint. It is a method used in the identification of the image that occupies a structural space which is greater than a lower structural space. The principal component analysis also identifies the region of small minutiae as well as the region of the actual minutiae of the image. Principal component analysis helps in the determination of the rotational as well as orientation aspect of objects.

Over seventy and less than one hundred small points are important I order to have prosperous rhyming in every two fingerprint portrait. Such formula is put into practice in the Gabor filter bank. This is an outcome of moving ridges revamps as well as Gaussian hells that are also referred to as sinusoids. Improves ridges and valley patterns to know as well as to extract symbol vectors to help in computing Euclidian length amidst two symbol vectors to help template matching.

\subsection{Analysis and results}

A formula of model-based is a bit more suitable compared to the formula of minutia-based since it occupies the entire image part of the fingerprint. Prior formula applied Pea that inevitably eliminates incorrect minutiae without the help of using the method of eliminating false minutiae. The number accurate points of bifurcation are raised by almost five to ten percent thereon using the solution that is recommended. The recommended outcome further discovers minutiae points that are not there that are previously lost during the previous algorithm.

Using the recommended outcome mentioned above all points of bifurcation correspondent are removed as well as the original highest number of marks is maintained that was previously very hard. The previous putting into practice was directed to increase extraction of in-depth marks of fingerprint 
identification as well as the comparison which improves rhyming formula of fingerprint robustness as wee as effectiveness.

\section{Conclusion}

The algorithm of fingerprint recognition improves the overall process of extraction of features especially the coming up with the small as well as the bifurcation of total marks. The above formula increases the certainty as well as the speed of correspondence. The formula regarding the rhyming pattern is cheaper as well as a bit faster based on minutiae formula.

The proposed formula does not limit the local characteristic of the fingerprint but it entails overall characteristic such as the profile of the ridges the position and direction of the crest and moving around etc. The Principal Component Analysis describes a pattern of the main constituent that assists you chose the prime key symbols. The leading merit of the Principal Component Analysis is its using fingerprint of lower dimension portrait that reduces complication. The filter of Gabor assists in investigating the occurrence of the folds as well as orientation. The Euclidian is a prime way to apply in matching the two models and easy to calculate in minimal time. The forthcoming task can easily be performed using the Principal component analysis recognition portrait fingerprint rate.

Filter Gabor, we the forthcoming tasks can easily be performed in the central area of the footprint while the identity could be defective whenever the focus is not correctly altered.

\section{References}

1. Liu N., Yin Y., Zhang H. A Fingerprint Matching Algorithm Based On Delaunay Triangulation Net 1. The Fifth International Conference on Computer and Information Technology (CIT'05). Shanghai, China: IEEE, 2005, pp. 591-595.

2. Francis-Lothai F., Bong D.B.L. A Fingerprint Matching Algorithm using Bit-Plane Extraction Method with Phase-Only Correlation. Int. J. Biom, 2017, vol. 9, no. 1, pp. 44-66. DOI: 10.1504/IJBM.2017.084135

3. Narwal S., Kaur D. Comparison between Minutiae Based and Pattern Based Algorithm of Fingerprint Image. International Journal of Information Engineering and Electronic Business, 2016, 8 (2), pp. 23-29. DOI: 10.5815/ijieeb.2016.02.03

4. Balti A., Sayadi M., Fnaiech F. Invariant and reduced features for Fingerprint Characterization. IECON 2012 - 38th Annual Conference on IEEE Industrial Electronics Society. Montreal, QC, Canada: IEEE, 2012, pp. 1530-1534. DOI: 10.1109/IECON.2012.6388514

5. Ganbawle A., Shaikh P.J.A. Implementation of Fingerprint Matching Algorithm. Int. J. Eng. Tech., 2016, vol. 2, no. 2, pp. 42-47.

6. Palanichamy J., Marimuthu R. A Novel Image Alignment and a Fast Efficient Localized Euclidean Distance Minutia Matching Algorithm for Fingerprint Recognition System. Int. Arab J. Inf. Technol., 2016, vol. 13, no. 6B, pp. 1061-1067.

7. Peralta D. et al. A Survey on Fingerprint Minutiae-based Local Matching for Verification and Identification: Taxonomy and Experimental Evaluation. Inf. Sci. (Ny). Elsevier Inc., 2015, vol. 315, pp. 67-87. DOI: 10.1016/j.ins.2015.04.013

8. Ahmed T., Sarma M. An Advanced Fingerprint Matching Using Minutiae-based Indirect Local Features. Multimed. Tools Appl. Springer US, 2017, vol. 77, no. 15, pp. 19931-19950. DOI: 10.1007/s11042-017-5444-9

9. Jain A.K., Feng J., Nandakumar K. Fingerprint Matching. Computer (Long. Beach. Calif), 2010, vol. 43, no. 2, pp. 36-44. DOI: 10.1109/MC.2010.38

10. Win Z.M., Sein M.M. An Efficient Fingerprint Matching System for Low Quality Images. Int. J. Comput. Appl., 2011, vol. 26, no. 4, pp. 12. DOI: 10.5120/3094-4246

11. Dyre S., Sumathi C.P. A Survey on Various Approaches to Fingerprint Matching for Personal Verification and Identification. Int. J. Comput. Sci. Eng. Surv, 2016, vol. 7, no. 4, pp. 1-17. DOI: $10.5121 /$ ijcses.2016.7401

12. Afsar F.A., Arif M., Hussain M. Fingerprint Identification and Verification System using Minutiae Matching. National Conference on Emerging Technologies, 2004, pp. 141-146.

13. Patel H., Asrodia P. Fingerprint Matching Using Two Methods. Int. J. Eng. Res. Appl., 2012, vol. 2, no. 3, pp. 857-860. 


\title{
Информатика и вычислительная техника
}

14. Ram S., Bischof H., Birchbauer J. Curvature Preserving Fingerprint Ridge Orientation Smoothing Using Legendre Polynomials. 2008 IEEE Computer Society Conference on Computer Vision and Pattern Recognition Workshops. Anchorage, AK, USA: IEEE, 2008, pp. 1-8. DOI: 10.1109/CVPRW.2008.4563118

15. Jie Y. et al. Fingerprint Minutiae Matching Algorithm for Real Time System. Pattern Recognit. Soc., 2006, vol. 39, no. 1, pp. 143-146. DOI: 10.1016/j.patcog.2005.08.005

16. Jain A., Ross A., Prabhakar S. Fingerprint Matching Using Minutiae and Texture Features. Proceedings 2001 International Conference on Image Processing (Cat. No.01CH37205). Thessaloniki, Greece: IEEE, 2001, pp. 282-285.

17. Peralta D. et al. Minutiae Filtering to Improve both Efficacy and Efficiency of Fingerprint Matching Algorithms. Eng. Appl. Artif. Intell., 2014, vol. 32. pp. 37-53. DOI: 10.1016/j.engappai.2014.02.016

18. Jain A.K., Feng J. Latent Fingerprint Matching. IEEE Trans. Pattern Anal. Mach. Intell., 2011, vol. 33, no. 1, pp. 88-100. DOI: 10.1109/TPAMI.2010.59

19. Pamplona Segundo, Lemes M. and de P.R. Pore Based Ridge Reconstruction for Matching. The IEEE Conference on Computer Vision and Pattern Recognition (CVPR) Workshops, 2015, pp. 128-133. DOI: 10.1109/CVPRW.2015.7301328

20. Kaur M. et al. Fingerprint Verification System using Minutiae Extraction Technique. Int. J. Comput. Electr. Autom. Control Inf. Eng., 2008, vol. 2, no. 10, pp. 3405-3410.

21. Mohammedsayeemuddin S., Pithadia P. V, Vandra D. A Simple and Novel Fingerprint Image Segmentation Algorithm. 2014 International Conference on Issues and Challenges in Intelligent Computing Techniques (ICICT). Ghaziabad, India: IEEE, 2014, pp. 756-759. DOI: 10.1109/ICICICT.2014.6781375

Received 25 March 2019

\section{КРАТКИЙ ОБЗОР МЕТОДОВ ИЗВЛЕЧЕНИЯ ПРИЗНАКОВ ИЗОБРАЖЕНИЙ ОТПЕЧАТКОВ ПАЛЬЦЕВ}

\author{
Х.И. Ваххаб, ${ }^{1,2}$, А.Н. Аль-Анссари ${ }^{1,3}$, Д.С. Рожина ${ }^{1}$, А.В. Агафонов ${ }^{1}$ \\ 1 Южно-Уральский государственный университет, г. Челябинск, Россия, \\ 2 Университет Кербелы, г. Кербела, Республика Ирак, \\ ${ }^{3}$ Университет Куфы, г. Наджаф, Республика Ирак
}

В настоящее время актуальны вопросы идентификации личности в области социальной политики, финансирования и криминалистики. Идентификация личности опирается на характеристики человека, такие как цвет глаз, отпечатки пальцев, лицо человека, подпись. Биометрические характеристики состоят из признаков, которые с помощью компьютерных технологий извлекаются из изображений этих характеристик, получаемых с устройств ввода. Наиболее широкое распространение получили компьютерные системы, распознающие отпечатки пальцев человека. Они получают изображения отпечатков пальцев с оптических устройств ввода, обрабатывают их, сохраняют признаки изображений в виде шаблонов в базе данных и сравнивают полученные шаблоны. По результатам сравнения шаблонов выполняется их распознавание.

Ключевые слова: соответствие отпечатков пальцев, улучшение изображения, сегментация, Габор фильтр. 
Ваххаб Хадер Ибас АбдулВаххаб, Южно-Уральский государственный университет, г. Челябинск; Университет Кербелы, г. Кербела, Республика Ирак; hader_wa@yahoo.com.

Аль-Анссари Алаа Неамах, Южно-Уральский государственный университет, г. Челябинск; Университет Куфы, г. Наджаф, Республика Ирак; alaan.azeez@ uokufa.edu.iq.

Рожина Дарья Сергеевна, аспирант кафедры электронных вычислительных машин, ЮжноУральский государственный университет, г. Челябинск; asp17rds604@susu.ru.

Агафонов Андрей Валерьевич, аспирант кафедры электронных вычислительных машин, Южно-Уральский государственный университет, г. Челябинск; asp17aav494@susu.ru.

Поступила в редакцию 25 марта 2019 2.

\section{ОБРАЗЕЦ ЦИТИРОВАНИЯ}

A Fingerprint Matching Algorithm / H.I. Wahhab, A.N. Alanssari, D.S. Rozhina, A.V. Agafonov // Вестник ЮУрГУ. Серия «Компьютерные технологии, управление, радиоэлектроника». - 2019. - Т. 19, № 4. C. 40-47. DOI: $10.14529 /$ ctcr190404

\section{FOR CITATION}

Wahhab H.I., Alanssari A.N., Rozhina D.S., Agafonov A.V. A Fingerprint Matching Algorithm. Bulletin of the South Ural State University. Ser. Computer Technologies, Automatic Control, Radio Electronics, 2019, vol. 19, no. 4, pp. 40-47. DOI: 10.14529/ctcr190404 